\title{
Inflação e Volatilidade de Preços Relativos: Evidências de Painéis Longos e Painel de Vetores Autoregressivos para a Economia Brasileira pós-Plano Real
}

\section{Inflation and Volatility of Relative Prices: Evidences from Long Panels and Panel of Vectors Autoregressive to the Brazilian Economy post-Real Plan}

\author{
Hugo Carcanholo Iasco Pereira* \\ Michel Cândido de Souza**
}

\begin{abstract}
Resumo: O objetivo do presente trabalho é investigar a relação entre inflação e volatilidade de preços e a presença de rigidez nominal para a economia brasileira após a adoção do Plano Real (julho de 1994 a maio de 2016). Para isso, calcula-se a volatilidade de preços relativos para as 11 capitais consideradas pelo IPCA e divide-se o período pós-Real até 2016 em três subperíodos, de acordo com as especificidades macroeconômicas identificadas. Os resultados das estimações sugerem que existe uma relação positiva entre a variação do nível de preços e a volatilidade de preços relativos da economia brasileira. Ademais, as estimações mostram que: a) a intensidade dessa relação se reduziu sistematicamente após o Plano Real; b) a adoção do sistema de metas de inflação contribuiu para a redução da volatilidade de preços relativos; e c) não há evidência de rigidez nominal para os três subperíodos, mas há evidência para o período todo.
\end{abstract}

Palavras-chave: Inflação. Volatilidade de preços relativos. Painéis econométricos.

Abstract: The objective of the present study was to investigate the relationship between inflation and price volatility and the presence of nominal rigidity for the Brazilian economy after the adoption of the Real Plan (from July 1994 to May 2016). The relative price volatility thereunto was calculated for the 11 capitals considered by the National Wide Consumer Price Index (IPCA). The post-Real period until 2016 was divided into three periods according to the identified macroeconomic specificities. The results of the estimations suggested that there is a positive relation between the inflation and relative price volatility. In addition, the estimates showed that: a) intensity of this relation was systematically reduced after the Plan Real; b) the adoption of the inflation targeting contributed to the reduction of relative price volatility; c) there is no evidence of nominal rigidities in the three sub periods, but there is in the all period.

Keywords: Inflation. Relative price volatility. Econometric panel.

\footnotetext{
* Doutorando em Economia Aplicada pelo Centro de Desenvolvimento e Planejamento Regional (Cedeplar) da Universidade Federal de Minas Gerais (UFMG). Bolsista CNPq. E-mail: hclpereira@ cedeplar.ufmg.br

** Doutorando em Economia Aplicada pelo Centro de Desenvolvimento e Planejamento Regional (Cedeplar) da Universidade Federal de Minas Gerais (UFMG). Professor da Universidade Federal dos Vales do Jequitinhonha e Mucuri (UFVJM). E-mail: mcsouza@cedeplar.ufmg.br
} 
JEL Classification: C23; C33; E31.

\section{Introdução}

A inflação é um fenômeno que sempre esteve presente ao longo da história econômica brasileira e seu controle efetivo é algo relativamente recente, que remonta ao Plano Real. Tal estratégia de estabilização possuiu como substrato analítico a teoria da inflação inercial, na qual o processo inflacionário passa a ser descolado da dinâmica de ajuste entre oferta e demanda agregada à medida que os agentes econômicos incorporam a taxa de inflação passada em seus preços para defender o respectivo nível de renda real. Paralelamente a essa literatura (mas com uma estrutura analítica totalmente diferente), os modelos novos keynesianos também fornecem explicações para uma dinâmica inflacionária associada à recessão, em que o trade-off da curva de Phillips não é válido, ou é alterado, e também sofre influência do componente defasado dos preços.

O cálculo do índice nacional de preços ao consumidor amplo (IPCA) pelo IBGE é uma média ponderada da variação de preços de uma cesta de bens para 11 capitais brasileiras (Goiânia, Brasília, Belém, Fortaleza, Recife, Salvador, Belo Horizonte, Rio de Janeiro, São Paulo, Curitiba e Porto Alegre). Diversos trabalhos estimaram a relação entre inflação e volatilidade de preços para a economia brasileira considerando o IPCA como essa média através de metodologias econométricas de séries temporais (SILVA; KADOTA, 1982; RESENDE; GRANDI, 1992; LANDAU; PEIXOTO, 1992; GOMES, 2007, 2015).

Não obstante, Balk (1983) ressalta que o nível de agregação do índice de inflação utilizado pode alterar os resultados obtidos. Tendo-se isso em mente, o objetivo deste trabalho é estimar a relação entre inflação e a volatilidade preços, tal como a possibilidade de rigidez nominal para a economia brasileira após a adoção do Plano Real (julho de 1994 a maio de 2016) com periodicidade mensal. Para tanto, utiliza-se o IPCA ao seu nível mais desagregado para o cálculo da volatilidade de preços de seus 11 municípios abrangidos para, então, se estimar tal relação por duas metodologias de painéis econométricos específicos à macroeconomia: a) panel corrected standard error (PCSE); e b) painel de vetores autoregressivos (PVAR). A metodologia é adequada porque é capaz de considerar a heterogeneidade da dinâmica da variação do nível de preços e da volatilidade ao nível mais desagregado (municipal) ao longo do tempo, tratando a possível correlação do termo de erro entre as unidades cross section e ao longo do tempo.

Argumenta-se que, ao se utilizar a taxa de inflação mensal nas estimações, supõe-se que o reajuste de preços da economia brasileira é perfeitamente sincronizado, ou, de outro modo, que todos os setores reajustem os seus preços ao mesmo tempo. A história recente pré-estabilização da economia brasileira mostra que tal suposição é bastante irrealista, já que todas as estratégias de estabilização 
procuravam desinflacionar o sistema econômico sincronizando de alguma maneira os reajustes de preços relativos. O êxito do Plano Real está fundamentalmente relacionado com o sucesso de implementar uma reforma monetária que zerasse a memória inflacionária através de um mecanismo de sincronização dos reajustes de preços de tal modo que não houvesse transferência de renda entre os agentes. Assim, além da abordagem metodológica original, busca-se contribuir com a literatura utilizando-se a taxa de inflação acumulada nos últimos 12 meses a partir de julho de 1994, supondo-se que esse intervalo seria suficiente para todos os setores reajustarem seus preços dentro de uma estrutura de reajuste de preços defasada. Nenhum dos trabalhos citados buscou uma análise desagregada dos indicadores de preço em relação aos municípios base para a média do cálculo do IPCA. Argumenta-se que uma estrutura econométrica de dados em painel pode proporcionar resultados mais robustos para a relação entre inflação e volatilidade de preços.

A estrutura deste trabalho está dividida da seguinte maneira: na segunda seção apresentam-se os referenciais teóricos inercialista e novo keynesiano, assim como a literatura empírica da área; na terceira seção abordam-se as metodologias econométricas; na quarta seção explanam-se os dados estatísticos e os modelos estimados; na quinta seção apresentam-se os resultados obtidos pelas estimações. Por fim, na sexta seção traçam-se as considerações finais.

\section{Inflação e Volatilidade de Preços em uma Perspectiva Teórica e Empírica}

A relação entre inflação e volatilidade de preços pode ser explicada por duas vertentes teóricas: a nova keynesiana e a inercialista, ambas com argumentos que sustentam uma relação positiva entre as duas variáveis.

A teoria nova keynesiana é fundamentada em uma estrutura analítica microfundamentada a partir dos trabalhos seminais de Blanchard (1987), Mankiw (1985) e Romer (1993), entre outros. A literatura nova keynesiana ressalta a rigidez de preços e salários como determinantes das flutuações cíclicas do emprego e da renda. Nesse sentido, a rigidez de preços advém do descolamento da dinâmica de preços do processo de ajustamento entre oferta e demanda agregada devido a imperfeições do mercado, como informação imperfeita, estrutura de mercado oligopolista, heterogeneidade setorial e custo de menu.

A literatura nova keynesiana incorpora a rigidez nominal na formação racional das expectativas de modo a otimizar a função de utilidade dos agentes. Uma dinâmica de preços bastante usada nesses modelos é a de Calvo (1983). As firmas escolhem alterar seus preços com a probabilidade (1- $-\theta)$, de modo que o nível evolui de acordo com uma média ponderada entre os valores ajustados e o nível de preços passado: 


$$
\mathrm{p}_{\mathrm{t}}=\theta \mathrm{p}_{\mathrm{t}-1}+(1-\theta) \mathrm{p}_{\mathrm{t}}^{*}
$$

em que $\mathrm{p}_{\mathrm{t}}$ representa o nível de preços no período corrente; $\mathrm{p}_{\mathrm{t}-1}$ é o nível de preços

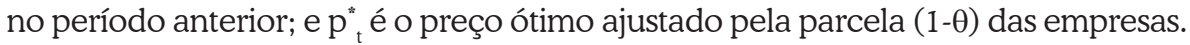

Considerando-se o custo marginal das empresas $\left(\mathrm{mc}_{1}\right)$, o valor natural desse custo $(\mu)$ e a taxa de desconto subjetiva ( $\beta)$, o preço ótimo escolhido pelo agente é:

$$
\mathrm{p}_{\mathrm{t}}^{*}=\mu+(1-\beta \theta) \sum_{\mathrm{k}=0}^{\infty}(\beta \theta)^{\mathrm{k}} \mathrm{E}_{\mathrm{t}}\left[\mathrm{mc}_{\mathrm{t}+\mathrm{kt}}+\mathrm{p}_{\mathrm{t}+\mathrm{k}}\right]
$$

Quando todas as firmas reajustam seus preços, o parâmetro $\theta$ assume valor igual a zero, e, logo, desvios de preço são iguais aos do custo marginal, portanto, os agentes escolhem os preços de acordo com o custo marginal esperado. Nesse caso, a volatilidade de preços relativos é nula porque os preços relativos se encontrarão inalterados. Todavia, se apenas uma parcela das firmas reajustar seus preços (o parâmetro $\theta$ é diferente de zero), os preços aumentarão à medida que o custo marginal esperado pelas firmas seja maior, afetando a volatilidade. Nota-se, então, que existe uma relação positiva entre a inflação e a volatilidade de preços relativos no escopo teórico novo keynesiano.

Por outro lado, na teoria inercialista, a inflação é um fenômeno real pautado pelo conflito distributivo entre os agentes econômicos ao redor da repartição do produto real. Nessa literatura, os trabalhos seminais são de Arida e Lara-Resende (1985) e Lopes (1985). À medida que a inflação significa um processo de transferência de renda real entre os agentes econômicos, estes procuram considerar a inflação passada na formulação de seus preços para defender a respectiva renda real. Isso significa que ocorre a reprodução das taxas pretéritas de inflação no presente, ou a inércia inflacionária, a qual, por definição, é descolada do processo de ajuste entre oferta e demanda agregada.

Em um processo inflacionário, os preços e rendimentos nominais aumentam. Contudo, a velocidade de crescimento dos preços dos setores com periodicidade de reajuste fixo (aluguéis e salários, por exemplo) é menor que a velocidade de ajustamento dos setores com reajuste automático (LOPES, 1985). Ou seja, a estrutura de preços relativos é defasada (a indexação de preços não é perfeita) já que os preços de alguns setores se encontram no valor de pico enquanto outros estão no vale. Esse diferencial de velocidade e defasagem dos preços relativos provoca uma transferência de renda real entre os agentes proporcional à diferença de velocidade de ajustamento dos preços relativos (LOPES, 1976). Os agentes procuram estabelecer o preço de seus produtos de modo a se defender desse processo de transferência de renda real.

A inflação deve ser entendida em razão dos picos da renda, da periodicidade dos reajustes e pela defasagem dos preços relativos da economia. Por conseguinte, 
quanto maior a pressão social dos agentes econômicos pela elevação dos picos de renda real e pela redução da periodicidade do reajuste da renda nominal, maior será a taxa de variação dos preços ou a volatilidade dos preços relativos (ARIDA; LARA-RESENDE, 1985). Nessa dinâmica, dois aspectos inter-relacionados são de grande importância na manutenção do nível da renda real dos agentes e na determinação da volatilidade dos preços relativos: o intervalo de reajuste e a taxa de inflação. Quanto maior a aceleração da variação do nível dos preços, menor será a memória inflacionária do sistema econômico, o que realimenta a taxa de inflação e aumenta a volatilidade dos preços relativos (ARIDA; LARA-RESENDE, 1985).

Em suma, na literatura inercialista, a volatilidade dos preços relativos está relacionada com a tentativa de os agentes defenderem a respectiva parcela relativa de renda real. Quanto maior a taxa de variação dos preços, os preços relativos se tornam mais voláteis porque os agentes defendem a respectiva renda real através dos reajustes de seus preços.

No tocante à literatura empírica, diversos trabalhos a nível internacional sugeriram uma relação positiva entre a taxa de inflação e a variabilidade dos preços relativos. Nesse sentido, tem-se o trabalho seminal de Parks (1978) como uma importante contribuição teórica em que se discute como se mensurar a volatilidade de preços relativos. Para isso, o autor utiliza regressões por mínimos quadrados ordinários $(\mathrm{MQO})$ para estimar a relação positiva entre inflação e volatilidade de preços relativos para a economia norte-americana. Fischer (1981) oferece uma excelente síntese dos argumentos novos keynesianos então desenvolvidos à época. Ademais, Fischer (1981) realiza um exercício econométrico comparando a relação entre volatilidade de preços relativos e inflação para os Estados Unidos, Japão e Alemanha, com ênfase em choques na oferta de alimentos e energia. Para tanto, o autor utiliza três metodologias: MQO, causalidade de Granger e vetores autoregressivos. Para a economia norte-americana, Parsley (1996) realiza um estudo com dados municipais utilizando a metodologia de painéis econométricos, mostrando que existe uma relação positiva entre ambas. Recentemente, Choi (2010) mostra que a relação entre inflação e preços relativos não é constante ao longo do tempo, nem linear para as economias americana e japonesa.

Balk (1983), por sua vez, utiliza o instrumental de séries temporais e dados para a Holanda para entender como o nível de agregação dos dados influencia os resultados estimados. A conclusão do autor sugere que o nível de agregação interfere nas inferências estatísticas dos parâmetros. Com isso, é importante um nível de desagregação alto, como o do presente trabalho, que, além de desagregar para todos os produtos considerados pelo IPCA, toma a inflação de cada município. Van Hoomissen (1988) utiliza a metodologia seemingly unrelated regression (SUR) para entender essa relação para Israel em relação a 13 subgrupos de bens. A autora conclui que, para todos os subgrupos, a referida relação é positiva. Jaramillo 
(1999) revisita o trabalho de Parks (1978) atualizando a base de dados para os Estados Unidos e obtém a mesma relação positiva entre as variáveis.

Alguns trabalhos tentaram estimar a relação entre a volatilidade dos preços relativos com a taxa de inflação para a economia brasileira. Silva e Kadota (1982) indicam uma relação positiva entre a taxa de inflação e a volatilidade dos preços relativos entre 1972 e 1980. Resende e Grandi (1992) testam a causalidade de Granger para essas duas variáveis para o período dos anos 1976 a 1985, não apresentando resultados conclusivos. Landau e Peixoto (1992) não encontram evidências de que a volatilidade dos preços relativos estaria relacionada positivamente com a taxa de inflação da economia brasileira da década de 1980. O argumento dos autores é que o complexo mecanismo de indexação presente à época infringiu uma dinâmica própria à volatilidade dos preços independente da taxa de inflação. Gomes (2007) estuda a relação entre o IPCA (e suas desagregações, preços livres, administrados, comercializáveis, não comercializáveis e serviços) e a volatilidade dos preços relativos através de modelos Arima-Garch, causalidade de Granger e funções resposta-impulso (IRF) a partir do Plano Real em 1994 e 2006. As conclusões do autor indicam que a adesão do regime de metas de inflação diminuiu a volatilidade dos preços relativos da economia brasileira.

\section{A Metodologia Econométrica}

Partindo-se de uma especificação com dados longitudinais, em que $x_{i, t}$ é o vetor de variáveis exógenas e $\mathrm{y}_{\mathrm{i}, \mathrm{t}}$ é o vetor de variáveis endógenas na unidade cross-section $i$ e na unidade temporal $t$, tem-se que:

$$
\mathrm{y}_{\mathrm{i}, \mathrm{t}}=\mathrm{x}_{\mathrm{i}, \mathrm{t}} \beta+\varepsilon_{\mathrm{i}, \mathrm{t}} \mathrm{i}=1, \ldots, \mathrm{N} ; \mathrm{t}=1, \ldots, \mathrm{T}
$$

O termo de erro é complexo, pois pode apresentar correlação temporal, dependência cross-section e heterocedasticidade. Assumir que os erros são independentes e homocedásticos implica um risco de que as estimações por MQO sejam inconsistentes e ineficientes, principalmente para dados relativos a variações de preços. Logo, um método econométrico de painéis que considere a correlação nessas duas dimensões e forneça estimadores consistentes é desejável. Para tal, elenca-se um modelo dessa categoria: o PCSE.

\subsection{Panel Corrected Standard Error (PCSE)}

A equação 3 pode ser estimada por mínimos quadrados generalizados (MQG) caso a matriz de covariância dos erros $\Omega$ seja conhecida. O MQG atua 
através da transformação do coeficiente estimado da equação 3, tornando os erros esféricos:

$$
\beta_{\{\mathrm{GLS}\}}=\left(\mathrm{X}^{\prime} \Omega^{-1} \mathrm{X}\right)^{-1} \mathrm{X}^{\prime} \Omega^{-1} \mathrm{Y}
$$

A matriz de covariância é:

$$
\operatorname{Cov}\left(\beta_{\{\mathrm{GLS}\}}\right)=\left(\mathrm{X}^{\prime} \Omega^{-1} \mathrm{X}\right)^{-1}
$$

No entanto, como, na prática, a matriz de covariância não é conhecida, o FGLS (feasible generalized least squares) utiliza uma estimação da mesma, $\widehat{\Omega}$. Esse procedimento, além de corrigir a correlação contemporânea, já corrige a heterocedasticidade. Parks (1967) utiliza pela primeira vez o procedimento FGLS para painéis. A transformação FGLS atua em duas etapas: primeiro, corrige a correlação contemporânea dos erros utilizando os resíduos da equação 3, escrevendo $\Omega=\Sigma \otimes \mathrm{I}_{\mathrm{T}}$, em que $\Sigma$ é matriz de covariância contemporânea, $\mathrm{E}_{\mathrm{t}}\left(\varepsilon_{\mathrm{i}, \mathrm{t}}, \varepsilon_{\mathrm{j}, \mathrm{t}}\right) ;{ }^{1}$ segundo, utilizando o resíduo da estimação com a correção da covariância contemporânea, Parks (1967) assume que o termo de erro segue um modelo AR (1), sendo que o termo $\mathrm{v}_{\mathrm{i}, \mathrm{t}}$ possui média zero e utiliza o parâmetro $\rho_{\mathrm{i}}$ para corrigir a correlação serial:

$$
\varepsilon_{\mathrm{i}, \mathrm{t}}=\rho_{\mathrm{i}} \varepsilon_{\mathrm{i}, \mathrm{t}-\mathrm{t}}+\mathrm{v}_{\mathrm{i}, \mathrm{t}}
$$

Beck e Katz (1995) argumentam que a transformação de Parks (1967) subestima a variância dos erros pelo fato de que a equação 3 é estimada apenas com base em T observações. Partindo dessa crítica ao modelo FGLS, Beck e Katz (1995) sugerem o PCSE como uma alternativa. Beck e Katz (1995) indicam que, se os erros são esféricos, os erros padrão da estimação OLS (ordinary least squares) estão corretos. Porém, se os erros são caracterizados por uma estrutura de dados longitudinais, a fórmula original está incorreta. Para um modelo de painel com correlação contemporânea e erros heterocedásticos, Beck e Katz (1995) mostram que os elementos da matriz $\Sigma$ podem ser estimados usando-se os resíduos da equação 3 através da equação 7 a seguir. À medida que $T$ aumenta, $\widehat{\Sigma}$ se torna um melhor estimador de $\Sigma$ :

$$
\widehat{\sum}_{i, j}=\frac{\sum_{t=1}^{T} \varepsilon_{i, t} \varepsilon_{j, t}}{T}
$$

1 A correção de Parks (1967) exige que T seja maior que N. 


\subsection{Painel de Vetores Autoregressivos (PVAR)}

O painel de vetores autoregressivos (PVAR) deriva da formulação original do VAR de Sims (1980), em que todas as variáveis endógenas são interpendentes ao longo do tempo, mas, adicionalmente, considera-se a relação cross sectional entre si. Tal metodologia econométrica foi introduzida por Holtz-Eakin, Newey e Rosen (1988). O PVAR possui a característica intrínseca de capturar a interpendência estática (a correlação cross sectional do termo de erro) e a dinâmica (lags de todas as variáveis endógenas), o que implica considerar a heterogeneidade cross sectional impondo uma estrutura específica à matriz de covariância dos termos de erro (CANOVA; CICARELLI, 2013). No escopo do presente trabalho, o PVAR foi estimado conforme Abrigo e Love (2016), com a seguinte estrutura de efeito fixo:

$$
\mathrm{y}_{\mathrm{i}, \mathrm{t}}=\mathrm{y}_{\mathrm{i}, \mathrm{t}-\mathrm{1}} \mathrm{A}_{1}+\mathrm{y}_{\mathrm{i}, \mathrm{t}-\mathrm{A}} \mathrm{A}_{2}+\cdots+\mathrm{y}_{\mathrm{i}, \mathrm{t}-\mathrm{p}+1} \mathrm{~A}_{\mathrm{p}-1}+\mathrm{y}_{\mathrm{i}, \mathrm{t}-\mathrm{p}} \mathrm{A}_{\mathrm{p}}+\mathrm{x}_{\mathrm{i}, \mathrm{t}} \mathrm{B}+\mathrm{u}_{\mathrm{i}}+\mathrm{e}_{\mathrm{i}, \mathrm{t}}
$$

em que $\mathrm{y}_{\mathrm{i}, \mathrm{t}}$ é um vetor $(1 \times k)$ de variáveis dependentes, $\mathrm{x}_{\mathrm{i}, \mathrm{t}}$ é um vetor $(1 \times L)$ de variáveis exógenas, $\mathrm{u}_{\mathrm{i}}$ é o efeito fixo, $\mathrm{e}_{\mathrm{i}, \mathrm{e}}$ é os erros idiossincráticos e os elementos $A$ e $B$ são os parâmetros a serem estimados. Em relação a erros, assume-se que $\mathrm{E}\left[\mathrm{e}_{\mathrm{i}, \mathrm{t}}\right]=0, \mathrm{E}\left[\mathrm{e}_{\mathrm{i}, \mathrm{t}}^{\prime} \mathrm{e}_{\mathrm{i}, \mathrm{t}}\right]=\Sigma$ e E[ $\left[\mathrm{e}_{\mathrm{i}, \mathrm{t}}^{\prime} \mathrm{e}_{\mathrm{i}, \mathrm{s}}\right]=0 \forall t>s$.

Reescrevendo a equação 8 de forma compacta, $y_{i, t}^{x}=\overline{y_{t, t}^{*}} A+e_{i, t}^{x}$, na qual $y_{i, t}^{x}$ é a primeira diferença $y_{i, t}^{*}=y_{i, t}-y_{i, t-1} \cdot e \cdot \overline{y_{t, t}^{*}}=\left(y_{i, t}-y_{i, t-1}\right)+\cdots+\left(y_{k, t}-y_{k, t-1}\right)$, o termo de erro é $e_{i, t}^{*}=\left(y_{i, t}^{*}-\overline{\overline{y_{t,}^{*}}}\right) \sqrt{T_{i, t} /\left(T_{i, t}+1\right)}$ e $\overline{\overline{y_{t, t}^{*}}}$ é a média de $y_{i, t}^{*}$. Logo, tem-se que o estimador GMM (generalized method of moments) é:

$$
A=\left(\overline{y^{*}} Z \widehat{W} Z^{\prime} \overline{y^{*}}\right)^{-1}\left(\overline{y^{*}} Z \widehat{W} Z^{\prime} \overline{y^{*}}\right)
$$

no qual $\widehat{W}$ é uma matriz de pesos de ordem $(L \times L)$ não singular, sendo a matriz que aumenta a eficiência do estimador. Como as equações estimadas pelo PVAR são de difícil interpretação, se concentrou o esforço analítico na interpretação das IRF, com intervalos de confiança simulados por bootstrap na função decomposição da variância do erro (FEVD) e no teste de causalidade de Granger para o PVAR.

\section{Apresentação dos Dados e dos Modelos Estimados}

A série utilizada para mensurar a taxa de inflação da economia brasileira nas estimações econométricas desta pesquisa foi o IPCA acumulado nos últimos 12 meses. Já a volatilidade de preços relativos é a variável rpu, calculada pelos autores. A periodicidade mensal dos dados respeita o intervalo entre julho de $1994 \mathrm{e}$ maio de 2016 (INSTITUTO BRASILEIRO DE GEOGRAFIA E ESTATÍSTICA, 2016). Neste trabalho, se utiliza a ideia de que a volatilidade dos preços relativos em um 
processo inflacionário é o desvio padrão (ou a variância) da inflação da estrutura econômica em relação à taxa de inflação média da economia como um todo (DEBELLE; LAMONT, 1997). Os dados foram dessazonalizados utilizando-se a metodologia autoregressive integrated moving average with exogenous input (Arimax13).

A fórmula para o cálculo do rpv é apresentada na equação 10, idêntica à de Gomes (2015):

$$
r p v_{t, n}=\sqrt{\frac{1}{b} \sum_{i=1} w_{t, n, i}\left(\pi_{t, n, i}-\pi_{t, n}\right)^{2}}
$$

na qual b é o número de itens considerados pelo cálculo do IPCA, $w_{t, n, i}$ é o peso do item no cálculo (fornecido pelo IBGE), é a inflação acumulada nos últimos 12 meses do setor $i$, no tempo $t$, no município $n$, ao passo que é o IPCA acumulado no tempo $t$ do município $n$.

A volatilidade dos preços relativos da economia brasileira foi calculada considerando-se os 11 municípios base do cálculo do IPCA (Goiânia, Brasília, Belém, Fortaleza, Recife, Salvador, Belo Horizonte, Rio de Janeiro, São Paulo, Curitiba e Porto Alegre) e todos os nove setores (alimentos e bebidas, habitação, artigos de residência, vestuário, transportes, saúde, despesas pessoais, educação e comunicação) (IBGE, 2016). As estatísticas descritivas para o IPCA e a volatilidade dos preços relativos da economia brasileira são apresentadas na Tabela 1. Observou-se que, entre julho de 1994 e maio de 2016, tanto a volatilidade de preços relativos quanto a taxa de inflação seguiram uma trajetória decrescente em termos de média, variância, valores máximos e valores mínimos.

Tabela 1 - Estatísticas descritivas

\begin{tabular}{|c|c|c|c|c|c|c|c|c|}
\hline \multirow{2}{*}{ Período } & \multicolumn{4}{|c|}{ rpv } & \multicolumn{4}{|c|}{ IPCA } \\
\hline & $\overline{\mathbf{X}}$ & $\sigma^{2}$ & $\mathbf{X}_{\max }$ & $\mathbf{X}_{\min }$ & $\overline{\mathbf{X}}$ & $\sigma^{2}$ & $\mathbf{X}_{\max }$ & $\mathbf{X}_{\text {min }}$ \\
\hline $\begin{array}{l}1994 \mathrm{~m} 7- \\
2016 \mathrm{~m} 5\end{array}$ & 16,35 & 178,57 & $\begin{array}{c}85,93 \\
\text { SP- } \\
1995 \mathrm{~m} 12\end{array}$ & $\begin{array}{c}4,11 \\
\text { SP-2010m8 }\end{array}$ & 7,98 & 27,10 & $\begin{array}{c}37,60 \\
\text { BE-1995m6 }\end{array}$ & $\begin{array}{c}0,75 \\
\text { SP- } \\
-1998 \mathrm{~m} 12\end{array}$ \\
\hline $\begin{array}{c}1994 \mathrm{~m} 7- \\
1999 \mathrm{~m} 7\end{array}$ & 30,61 & 455,50 & $\begin{array}{c}85,93 \\
\text { SP- } \\
-1995 \mathrm{~m} 12\end{array}$ & $\begin{array}{c}4,19 \\
\text { BS-1999m1 }\end{array}$ & 11,33 & 75,72 & $\begin{array}{c}37,60 \\
\text { BH-1995m6 }\end{array}$ & $\begin{array}{c}0,75 \\
\text { SP- } \\
-1998 \mathrm{~m} 12\end{array}$ \\
\hline $\begin{array}{l}1999 \mathrm{~m} 8- \\
2008 \mathrm{~m} 12\end{array}$ & 13,38 & 20,50 & $\begin{array}{c}33,33 \\
\text { BS- } \\
-1999 \mathrm{~m} 11\end{array}$ & $\begin{array}{c}5,01 \\
\text { SP-2004m8 }\end{array}$ & 7,39 & 12,33 & $\begin{array}{c}21,11 \\
\text { BS-2003m4 }\end{array}$ & $\begin{array}{c}1,69 \\
\text { RJ-2000m1 }\end{array}$ \\
\hline $\begin{array}{l}2009 \mathrm{ml}- \\
2016 \mathrm{~m} 5\end{array}$ & 10,56 & 12,58 & $\begin{array}{c}24,67 \\
\text { FO- } 2013 \mathrm{~m} 4\end{array}$ & $\begin{array}{c}4,11 \\
\text { SP-2010m8 }\end{array}$ & 6,45 & 3,14 & $\begin{array}{c}12,79 \\
\text { CU-2015m12 }\end{array}$ & $\begin{array}{c}2,69 \\
\text { GO-2010m6 }\end{array}$ \\
\hline
\end{tabular}

Fonte: Elaboração própria a partir de Instituto Brasileiro de Geografia e Estatística (2016). 
Os Gráficos 1 e 2 apresentam a dinâmica da taxa de inflação acumulada nos últimos 12 meses e a volatilidade de preços relativos dos municípios brasileiros entre julho de 1994 e maio de 2016.

Gráfico 1 - IPCA acumulado pelos últimos 12 meses entre julho de 1994 e maio de 2016

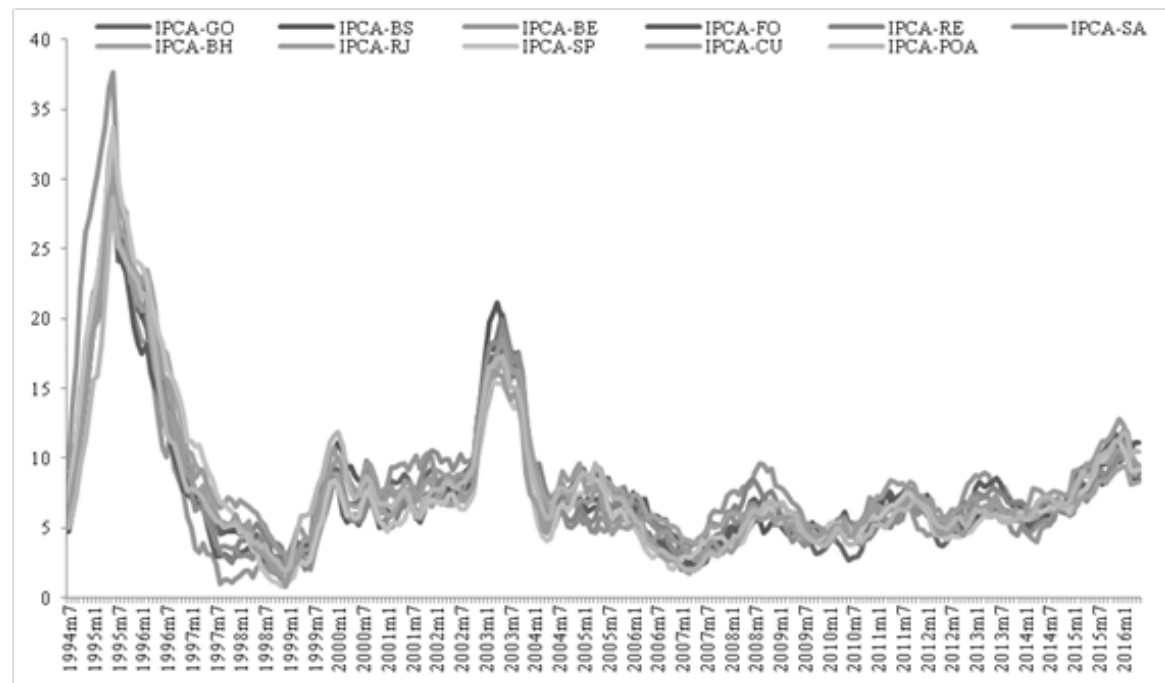

Fonte: Elaboração própria a partir de Instituto Brasileiro de Geografia e Estatística (2016).

Gráfico 2 - Volatilidade dos preços relativos entre julho de 1994 e maio de 2016

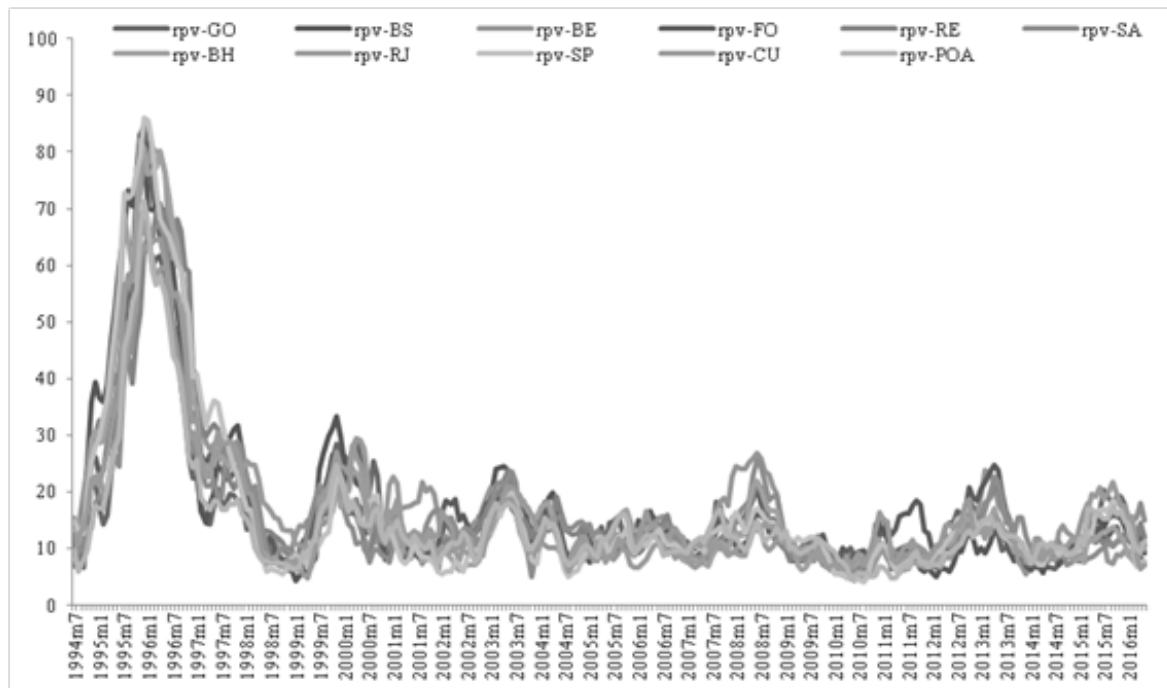

Fonte: Elaboração própria a partir de Instituto Brasileiro de Geografia e Estatística (2016). 
É possível perceber, nos Gráficos 1 e 2, três grandes períodos nas variáveis, com as seguintes características:

a) julho de 1994 a julho de 1999: o êxito da estabilização do Plano Real se refletiu na dinâmica de desaceleração da taxa de inflação acumulada nos últimos 12 meses dos municípios brasileiros, tal como a diminuição da volatilidade de preços relativos no período pós-junho de 1994. O Plano Real conseguiu de fato reduzir a memória inflacionária da economia brasileira de tal modo que a inércia, ou a reprodução das taxas pretéritas de inflação no presente, deixou de fazer sentido no comportamento crônico dos agentes de alterar os respectivos preços relativos para defender a consequente renda real na renda nacional. Logo, a volatilidade dos preços relativos acompanhou o comportamento da taxa de inflação;

b) agosto de 1999 a dezembro de 2008: a crise cambial de 1999 teve um efeito aceleracionista no nível de preços e na volatilidade dos preços relativos da economia brasileira, levando-a a um patamar de inflação mais elevado em relação ao pós-Plano Real, com forte elevação no período da eleição de 2002 por conta do "efeito Lula" e a consequente desvalorização da moeda nacional frente ao dólar. A política anticíclica do governo como reação à crise de 2008 provocou uma aceleração da taxa de inflação e da volatilidade dos preços relativos;

c) janeiro de 2009 a maio de 2016: entre altos e baixos, a taxa de inflação acumulada dos 12 meses se estabilizou em torno de uma média após a crise de 2008. Contudo, dois fatores contribuíram para a recente elevação da taxa de inflação e da volatilidade de preços: a depreciação cambial como uma reação à reeleição de Dilma e o descongelamento dos preços públicos administrados do governo Dilma II.

Utilizando-se a metodologia PCSE, ${ }^{2}$ estimar-se-ão dois modelos para a economia brasileira, dispostos nas equações 11 e 12 . O objetivo da equação 11 é capturar a relação entre o comportamento dos preços relativos à dinâmica da taxa de inflação, tal como Parks (1978) e Debelle e Lamont (1997). Originalmente, a literatura utiliza defasagens da variável dependente rpv e o valor modular da taxa de inflação como regressor. Não obstante, utilizar a taxa de inflação acumulada dos últimos 12 meses possui duas implicações:

a) a magnitude da variação de preços será sempre positiva (ver Gráfico 1), portanto não faz sentido especificar o modelo em valores absolutos;

2 Os testes de raiz unitária para painéis (ver Apêndice A) indicaram que as variáveis IPCA e rpv são estacionárias em nível, ou seja, ambas são I(0). Assim, as regressões foram estimadas com as variáveis em nível. 
b) a defasagem da variável explicativa (rpv) já está incorporada indiretamente ao se utilizar o IPCA acumulado (tanto no cálculo da volatilidade de preços quanto da inflação acumulada).

Com isso, a primeira especificação de modelo estimado é:

$$
\mathrm{rpv}_{\mathrm{t}}=\mathrm{B}_{0}+\alpha \pi_{\mathrm{t}}+\varepsilon_{\mathrm{t}}
$$

Jaramillo (1999) sugere que é possível captar a rigidez nominal da economia adicionando uma dummy no modelo a ser estimado. A não rigidez nominal (flexibilidade) implica que variações positivas e negativas na taxa de inflação geram variações proporcionais na volatilidade dos preços. Entretanto, se há rigidez nominal, aumentos na taxa de inflação aumentam a volatilidade, mas reduções na taxa de inflação não têm qualquer impacto na volatilidade de preços (JARAMILLO, 1999). Adicionar-se-á uma dummy na segunda especificação do modelo a ser estimado para se capturar o efeito da redução do nível da inflação (IPCA) sob a volatilidade dos preços relativos conforme a metodologia empregada por Parks (1978): zero para valores positivos e um para taxas negativas, multiplicando pelo valor do IPCA. Em termos econométricos, se o coeficiente dessa dummy não é estatisticamente significante, descarta-se a hipótese de rigidez nominal (JARAMILLO, 1999).

Jaramillo (1999) sugere incorporar essa dummy multiplicando-a pelo valor modular da taxa de inflação. Na especificação da equação 12, a dummy é introduzida multiplicada pela variação da taxa de inflação acumulada: ${ }^{3}$

$$
\mathrm{rpv}_{\mathrm{t}}=\mathrm{B}_{0}+\mathrm{B}_{1} \pi_{\mathrm{t}}+\mathrm{B}_{3} \mathrm{~d} \Delta \pi_{\mathrm{t}}+\varepsilon_{\mathrm{t}}
$$

A estimação do modelo de PVAR foi feita nos moldes da equação 11. Por fim, considerando-se as especificidades macroeconômicas da economia brasileira sintetizadas anteriormente, as equações 11 e 12 foram estimadas através das metodologias econométricas para quatro períodos: a) julho de 1994 a maio de 2016; b) julho de 1994 a julho de 1999 (pós-Plano Real); c) agosto de 1999 a dezembro de 2008 (adesão ao regime de metas de inflação para a crise de 2008); d) janeiro de 2009 a maio de 2016. Os resultados são apresentados a seguir.

3 Cabe notar que, como a inflação acumulada nos últimos 12 meses é sempre positiva, a dummy foi adicionada na situação em que o IPCA acumulado diminuiu - o que equivale a pensar que a taxa de inflação mensal se reduziu. Considerando-se os 11 municípios, para cada período têm-se, respectivamente, os seguintes episódios de redução do IPCA acumulado: a) julho de 1994 a julho de 1999 (366); b) agosto de 1999 a dezembro de 2008 (621); e c) janeiro de 2009 a maio de 2016 (464). 


\section{Resultados das Estimações Econométricas}

A seguir, apresentam-se os resultados das estimações econométricas.

\subsection{As Estimações PCSE}

As estimações da equação 11 são apresentadas na Tabela 2. O modelo PCSE sugere uma relação positiva entre a taxa de inflação e a volatilidade de preços da economia brasileira para os quatro períodos. Todos os coeficientes estimados são estatisticamente significantes ao nível de 1\% de significância.

Tabela 2 - Resultados do modelo sem a dummy de deflação

\begin{tabular}{|c|c|c|c|c|c|c|}
\hline Período & Constante & $\operatorname{IPCA}(\alpha)$ & $\mathbf{R}^{2}$ & $\mathbf{T}$ & $\mathbf{N}$ & $\lambda$ \\
\hline $\begin{array}{l}1994- \\
2016\end{array}$ & $\begin{array}{c}4,37^{* *} \\
(2,03)[0,03]\end{array}$ & $\begin{array}{c}1,46 * * * \\
(0,13)[0,00]\end{array}$ & 0,26 & 263 & 11 & 0,83 \\
\hline $\begin{array}{l}1994 \mathrm{mb}- \\
-1999 \mathrm{~m} 7\end{array}$ & $\begin{array}{c}10,69 * \\
(5,74)[0,06]\end{array}$ & $\begin{array}{c}1,67 * * * \\
(0,30)[0,00]\end{array}$ & 0,28 & 60 & 11 & 0,76 \\
\hline $\begin{array}{l}1999 \mathrm{~m} 8- \\
-2008 \mathrm{ml2}\end{array}$ & $\begin{array}{c}8,73 * * * \\
(0,08)[0,00]\end{array}$ & $\begin{array}{c}0,66 * * \\
(0,08)[0,00]\end{array}$ & 0,24 & 114 & 11 & 0,76 \\
\hline $\begin{array}{l}2009 \mathrm{ml}- \\
-2016 \mathrm{~m} 5\end{array}$ & $\begin{array}{c}4,24 * * * \\
(1,29)[0,00]\end{array}$ & $\begin{array}{c}0,97 * * \\
(0,177)[0,00]\end{array}$ & 0,16 & 89 & 11 & 0,70 \\
\hline
\end{tabular}

Fonte: Elaboração própria a partir dos resultados estimados.

Os coeficientes estimados diferiram entre os períodos, o que fornece indicações de que a relação entre volatilidade de preços e inflação não foi constante ao longo do tempo. No período imediato ao pós-Plano Real (1994-1999), o coeficiente $\alpha$ foi o maior em relação aos outros $(1,67)$, enquanto que, entre 1999-2008, foi o menor $(0,66)$, mas, entre 2009-2016, voltou a se elevar $(0,97)$, como visto na Tabela 2.

As estimações da equação 12 com a dummy indicaram a mesma dinâmica para o coeficiente $\alpha$ : valor relativamente mais alto entre 1994 e $1999(1,72)$; entre 1999 e 2008 se reduz para o valor mais baixo $(0,68)$; mas aumenta entre 2009 e 2016 (0,96). As estimações sugerem que a dummy não é significativa para nenhum dos três períodos específicos, mas que é significativa para toda a extensão temporal entre 1994 e 2016, como pode ser visto na Tabela 3. 
Tabela 3 - Resultados do modelo com a dummy de deflação

\begin{tabular}{cccccccc}
\hline Periodo & Constante & IPCA $(\alpha)$ & $\mathbf{d} \boldsymbol{\Delta}_{\mathbf{t}}$ & $\mathbf{R}^{\mathbf{2}}$ & $\mathbf{T}$ & $\mathbf{N}$ & $\boldsymbol{\lambda}$ \\
\hline $1994-$ & $3,46^{*}$ & $1,55^{* * *}$ & $-7,60 * *$ & \multirow{2}{*}{0,27} & 263 & 11 & 0,80 \\
2016 & $(1,85)[0,06]$ & $(0,13)[0,00]$ & $(2,88)[0,00]$ & 0,27 & & & \\
$1994 \mathrm{~m} 6-$ & $9,57 *$ & $1,72 * *$ & $-12,86$ & & & & \\
$-1999 \mathrm{~m} 7$ & $(5,22)[0,06]$ & $(0,29)[0,00]$ & $(9,26)[0,16]$ & 0,30 & 60 & 11 & 0,71 \\
$1999 \mathrm{~m} 8-$ & $8,55^{* * *}$ & $0,68 * *$ & $-1,29$ & & & & \\
$-2008 \mathrm{~m} 12$ & $(0,93)[0,00]$ & $(0,90)[0,00]$ & $(1,66)[0,43]$ & 0,24 & 114 & 11 & 0,76 \\
$2009 \mathrm{~m} 1-$ & $4,31^{* * *}$ & $0,96 * *$ & 0,76 & & & & \\
$-2016 \mathrm{~m} 5$ & $(1,34)[0,00]$ & $(0,18)[0,00]$ & $(2,39)[0,75]$ & 0,16 & 89 & 11 & 0,70 \\
\hline
\end{tabular}

Fonte: Elaboração própria.

Com a finalidade de se verificar se os parâmetros estimados são estatisticamente diferentes entre os períodos, realizou-se o teste de Wald. Percebeu-se que o parâmetro para o período entre agosto de 1999 e dezembro de 2008 difere do parâmetro do período imediato ao Plano Real (Chi2 $=135,73$ e p-valor de 0.00). No entanto, notou-se que o parâmetro para o período entre janeiro de 2009 e maio de 2016 não difere estatisticamente do parâmetro do período anterior (Chi2 $=3,05$ e $p$-valor de 0,08 ).

\subsection{Resultados das Estimações do Painel de Vetores Autoregressivos (PVAR)}

A análise anterior, baseada no estimador PCSE, fornece bons insights a respeito da relação entre inflação e volatilidade de preços. Contudo, procura-se avançar na investigação da direção causal (no sentido de Granger) e na resposta em relação a possíveis choques nessas variáveis através da abordagem PVAR e pelo teste de causalidade de Granger para PVAR.

A seleção do número de defasagens da estimação PVAR, em cada período, foi realizada através da análise de critérios de informação específicos para modelos de painel autorregressivo: critério de informação bayesiano (MBIC), critério de informação Akaike (MAIC) e critério de informação Hannan-Quin (MQIC). Foram utilizadas as respectivas defasagens nas estimações para cada período: 1994-2016 (2), 1994m6-1999m7 (2), 1999m8-2008m12 (3) e 2009m1-2016m5 (2), conforme a Tabela 5 (ver Apêndice A). Todos os modelos estimados satisfazem a condição de estabilidade, sendo possível, portanto, a representação do sistema como um MA $(\infty)$ e, então, a interpretação das IRF e a FEVD.

A Figura 1 apresenta a IRF com um horizonte temporal de dez meses dos modelos PVAR estimados. Para o período inteiro entre o Plano Real em 1994 e 2016 (primeiro quadrante da esquerda da Figura 1), um choque de um desvio padrão no IPCA provocou um aumento da volatilidade dos preços relativos do 
sistema (como esperado de acordo com a literatura), que se estabiliza na média a partir do décimo mês. Já um choque de um desvio padrão na volatilidade de preços aumenta o IPCA até o terceiro mês, a partir do qual converge à média. Entretanto, ao se separar esse período em horizontes temporais menores conforme eventos históricos, percebe-se que a relação entre as variáveis do sistema não foi uniforme.

Figura 1- Função resposta-impulso (IRF) do PVAR para 1994-2016, 1994m61999m7, 1999m8-2008m12 e 2009m1-2016m5

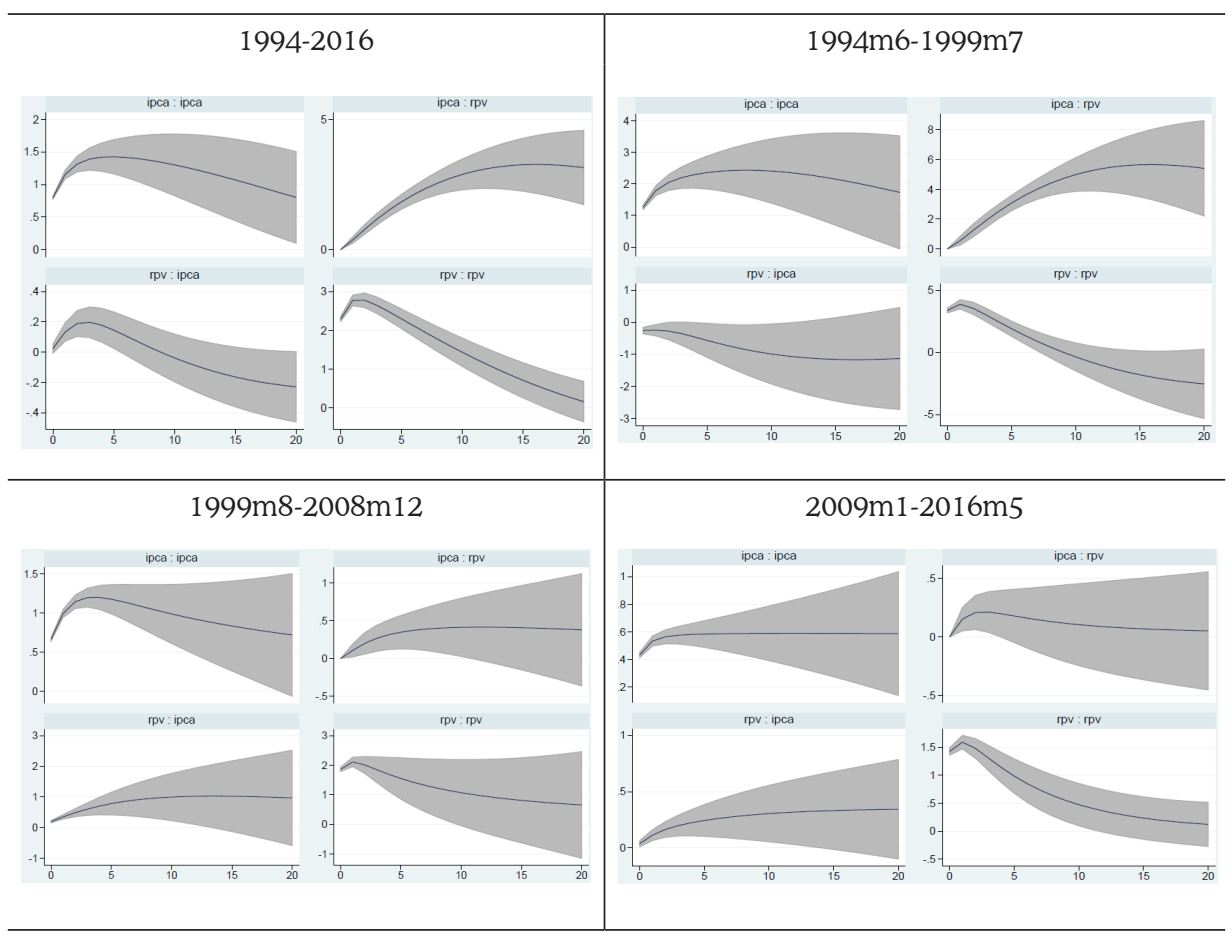

Fonte: Elaboração própria a partir dos resultados do PVAR.

Um choque no IPCA provocou variações positivas na volatilidade de preços nos três períodos em questão. Não obstante, a intensidade do choque diferiu entre eles. Após a estabilização da economia brasileira em 1994, a intensidade de um choque inflacionário na volatilidade de preços se reduziu sistematicamente, sobretudo após a adoção do regime de metas de inflação em 1999, seguindo tal trajetória até 2016.

Por outro lado, impactos de choques da volatilidade de preços no IPCA, além de diferirem em intensidade, também divergem em sinal. No período imediato à estabilização da economia brasileira em 1994, a relação entre a volatilidade preços e o IPCA é negativa, o que reflete o êxito do Plano Real em controlar a inflação. To- 
davia, isso se modifica a partir da adoção do regime de metas de inflação, porque tal relação se tornou positiva, mantendo-se positiva, mas diferiu em intensidade entre os períodos de agosto de 1999 a dezembro de 2008 e de janeiro de 2009 a maio de 2015, no sentido de choques na volatilidade de preços causarem variações positivas menores na inflação.

A Figura 2 apresenta a FEVD dos modelos estimados para os quatro períodos. A participação do IPCA na variância do erro de previsão da volatilidade de preços até o décimo mês, por período analisado, é de 38\% (1994 a 2016), 60\% (junho de 1994 a julho de 1999), 0,04\% (agosto de 1999 a dezembro de 2008) e 0,02\% (janeiro de 2009 a maio de 2016). Já em relação ao quanto a volatilidade de preços explica a variância do erro de previsão da inflação, têm-se 0,01\% (1994 a 2016), 0,07\% (junho de 1994 a julho de 1999), 0,31\% (agosto de 1999 a dezembro de 2008) e 0,13\% (janeiro de 2009 a maio de 2016). Nota-se, portanto, que a decomposição da variância do erro de previsão mudou ao longo dos períodos analisados. 
Figura 2 - Função de decomposição da variância (FEVD)

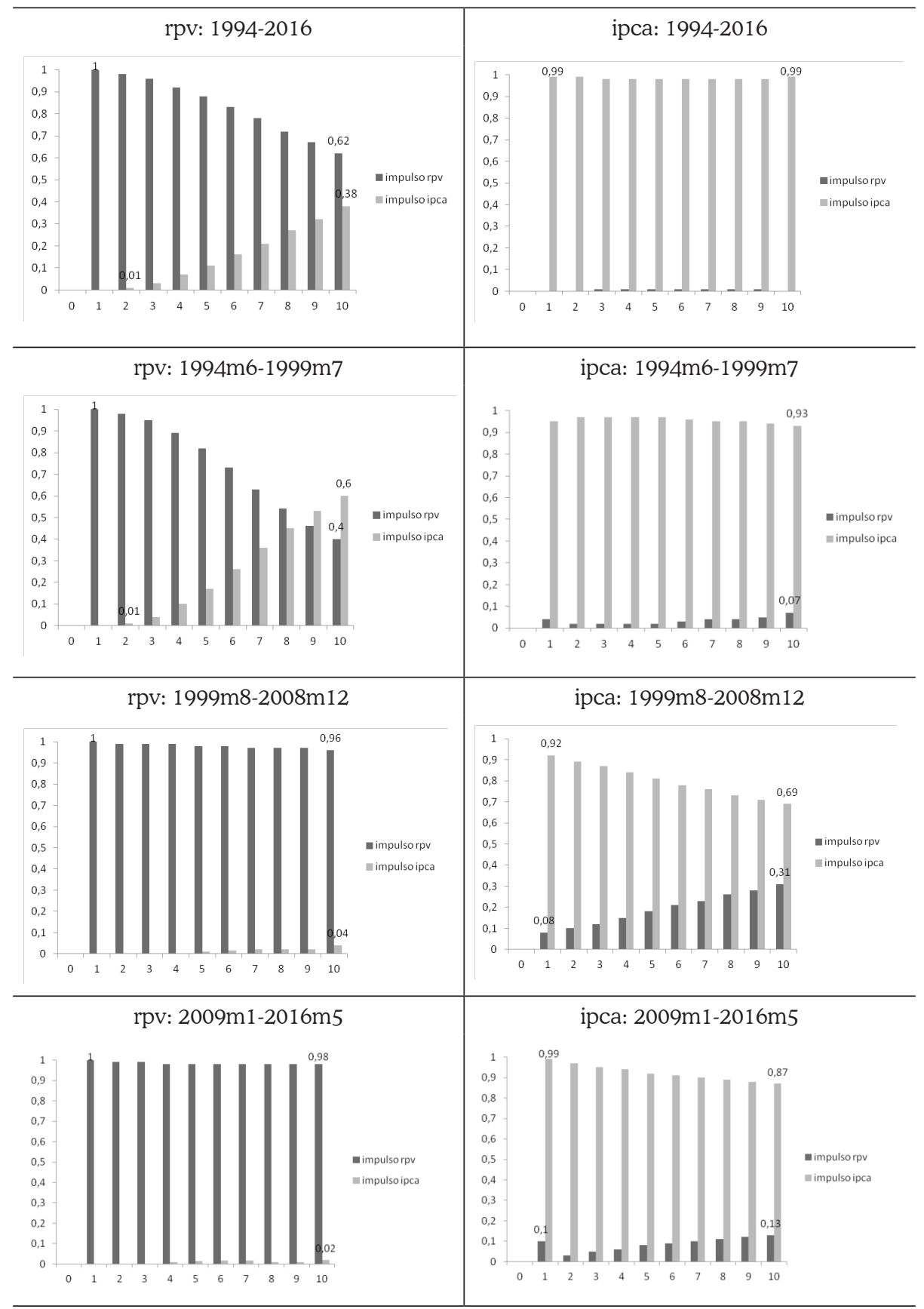

Fonte: Elaboração própria a partir dos resultados do PVAR. 
O teste de Granger é apresentado na Tabela 4.

Tabela 4- Teste Wald de causalidade PVAR-Granger

\begin{tabular}{c|c|c|c|c|c|c}
\hline Período & Equação & Excluído & $\chi^{\mathbf{2}}$ & GL & Prob $>\chi^{\mathbf{2}}$ & $\begin{array}{c}\text { Granger } \\
\text { causa (5\%)? }\end{array}$ \\
\hline \multirow{2}{*}{$1994-2016$} & rpv & ipca & 95,98 & 2 & 0,000 & Sim \\
& ipca & rpv & 39,55 & 2 & 0,000 & Sim \\
\hline \multirow{2}{*}{$1994 \mathrm{m6}-1999 \mathrm{~m} 7$} & rpv & ipca & 71,44 & 2 & 0,000 & Sim \\
& ipca & rpv & 27,62 & 2 & 0,000 & Sim \\
\hline \multirow{2}{*}{ 1999m8- } & rpv & ipca & 8,89 & 2 & 0,012 & Sim \\
$-2008 m 12$ & ipca & rpv & 8,20 & 2 & 0,017 & Sim \\
\hline \multirow{2}{*}{$2009 m 1-2016 m 5$} & rpv & ipca & 7,59 & 2 & 0,022 & Sim \\
& ipca & rpv & 16,74 & 2 & 0,000 & Sim \\
\hline
\end{tabular}

Fonte: Elaboração própria a partir dos resultados do PVAR.

Constata-se que, ao nível de significância de 5\%, IPCA Granger causa volatilidade de preços e que a variável volatilidade de preços Granger causa IPCA para todos os períodos, incluindo o intervalo de tempo entre 1994 e 2016. Ou seja, existe causalidade bidirecional, no sentido de Granger, entre as variáveis em todos os períodos delineados nesta pesquisa.

\section{Considerações Finais}

O cálculo do IPCA nacional pelo IBGE é uma média ponderada da evolução de uma cesta de bens para 11 capitais brasileiras (Goiânia, Brasília, Belém, Fortaleza, Recife, Salvador, Belo Horizonte, Rio de Janeiro, São Paulo, Curitiba e Porto Alegre). Diversos trabalhos estimaram a relação entre inflação e volatilidade de preços considerando o IPCA nacional. O objetivo do presente trabalho foi explorar a relação entre inflação e volatilidade de preços entre o período imediato pós Plano Real de agosto de 1994 a maio de 2016 para a economia brasileira. Este trabalho utilizou o IPCA de cada município no cômputo da relação entre inflação e volatilidade de preços relativos através da metodologia econométrica de painéis longos e painel de vetores autoregressivos. A principal razão dessa abordagem proposta é o ganho de informações normalmente ignorado quando se utiliza o IPCA como uma média dessa variável para os municípios brasileiros.

A fundamentação teórica do Plano Real encontra respaldo analítico na interpretação inercialista. O objetivo dessa estratégia de estabilização foi implementar uma reforma monetária para zerar a memória inflacionária do sistema econômico brasileiro e, por conseguinte, controlar o processo hiperinflacionário. No escopo deste trabalho, isso significa reduzir a volatilidade de preços relativos através da 
redução da taxa de crescimento do nível de preços. Tendo-se em mente o êxito do Plano Real em fazê-lo e que a estrutura de indexação da economia brasileira é dessincronizada (o que no novo keynesianismo se traduz em um parâmetro diferente de zero), este trabalho tentou contribuir com a literatura incorporando esses elementos por meio do IPCA acumulado dos últimos 12 meses a partir de julho de 1994 (imediatamente após o Plano Real), supondo que 12 meses é o suficiente para todos os setores da economia brasileira repassar a inflação passada para os respectivos preços.

Em consonância ao objetivo do trabalho, foram estimados modelos econométricos pelas metodologias PCSE e PVAR, com periodicidade mensal de julho de 1994 a maio de 2016, e, adicionalmente, para mais três subperíodos definidos por especificidades históricas da economia brasileira: a) o período imediato pós-Plano Real e a adoção do regime de metas de inflação (junho de 1994 e julho de 1999); b) após adoção do regime de metas de inflação e a crise de 2008 (agosto de 1999 e dezembro de 2008); e c) no pós-crise de 2008 (janeiro de 2009 e maio de 2016).

A estimação por PCSE sugeriu uma relação positiva entre inflação e a volatilidade de preços. Porém, essa relação não é constante ao longo do tempo já que o coeficiente estimado (significante ao nível de 1\%) foi mais elevado no período imediato à implementação do Plano Real, atingindo o menor valor entre a adoção do regime de metas de inflação e a crise de 2008 e se elevando a partir de então. Cabe ressaltar que o teste de Wald confirmou que os parâmetros estimados diferem estatisticamente entre os períodos. Os resultados obtidos devem ser analisados à luz das políticas macroeconômicas dos períodos em questão. O elevado coeficiente obtido para a extensão temporal entre 1994 e 1999 é resultado do processo de redução da taxa de variação do nível de preços por meio do Plano Real, como pôde ser visto nos Gráficos 1 e 2 e na Tabela 1. O coeficiente obtido entre 1999 e 2008 (menor dos estimados) é resultado da adoção do regime de metas de inflação. Por fim, o período entre a crise de 2008 e 2016 é notoriamente marcado pela adoção de congelamento e, posteriormente, descongelamento de preços e tarifas públicas pelos governos Dilma I e II, o que explica o diferencial positivo de magnitude do parâmetro.

Em relação ao modelo com dummy, a estimação por PCSE indicou que, ao nível de 1\% de significância, pode-se descartar a hipótese nula de não significância estatística para o período entre 1994 e 2016, ou seja, não se pode rejeitar a hipótese de rigidez nominal para essa extensão temporal. Porém, esse período é demasiadamente extenso. Ao se considerar as especificidades macroeconômicas desses 22 anos, o modelo PCSE sugeriu que todas as dummies dos três subperíodos são estatisticamente não significantes, isto é, não há evidências de rigidez nominal ao se considerar as especificidades macroeconômicas de cada período. 
As IRF obtidas pelo PVAR também indicaram uma relação positiva entre inflação e volatilidade de preços, mas a intensidade de um choque de um desvio padrão no IPCA diferiu substancialmente entre os subperíodos. As estimações sugeriram que a intensidade se reduziu sistematicamente após 1994, atingindo o menor patamar no subperíodo do pós-crise de 2008. Percebeu-se que, após a adoção do regime de metas de inflação, a intensidade do impacto de um choque no IPCA sob a volatilidade de preços diminuiu bastante em relação ao período imediato ao Plano Real, isto é, a convergência da variável volatilidade de preços se deu em valores bastante menores para os dois períodos entre agosto de 1999 e dezembro de 2008 (sobretudo nesse) e janeiro de 2009 e maio de 2016. Em suma, os resultados do PVAR estão de acordo com os resultados das estimações por PCSE de que a adoção do regime de metas de inflação proporcionou a redução da volatilidade de preços.

\section{Referências}

ABRIGO, R. M. M.; LOVE, I. Estimation of panel vector autoregression in Stata. Stata Journal, v. 16, n. 3, p. 778-804, 2016.

ARIDA, P.; LARA-RESENDE, A. Inertial inflation and monetary reform in Brazil. Rio de Janeiro, 1985. (Texto para discussão PUC/RJ nº 85).

BALK, B. M. Does there exist a relation between inflation and relative price-change variability? The effect of the aggregation level. Economic Letters, v. 13, p. 173-180, 1983.

BECK, N.; KATZ, J. What to do (and not to do) with time-series cross-section data. The American Political Science Review, v. 89, n. 3, p. 634-647, 1995.

BLANCHARD, O. J. Why does money affect output? A survey. Cambridge, MA, US, June 1987. (NBER Working Paper n. 2285).

CALVO, G. Staggered prices in a utility maximizing framework. Journal of Monetary Economics, v. 3, n. 12, p. 383-398, 1983.

CANOVA, F.; CICCARELLI, M. Panel vector autoregressive models: a survey. Frankfurt am Main, Germany, Jan. 2013. (Working Paper Series n. 1507).

CHOI, C.-Y. Reconsidering the relationship between inflation and relative price variability. Journal of Money, Credit and Banking, v. 45, n. 5, p. 769-799, 2010.

DEBELLE, G.; LAMONT, O. Relative price variability and inflation: evidence from US cities. Journal of Political Economy, v. 105, n. 1, p. 132-152, 1997.

FISCHER, S. Relative shocks, relative price variability, and inflation. Brooking Papers on Economic Activity, v. 1981, n. 2, p. 381-441, 1981.

GOMES, C. Política monetária e variabilidade dos preços relativos: uma análise do caso brasileiro. In: ENCONTRO NACIONAL DE ECONOMIA DA ANPEC, 35., 2007, 
Pernambuco. Anais... Niterói: ANPEC, 2007. p. 2-20. Disponível em: <http://www.anpec. org.br/encontro2007/artigos/A07A067.pdf> . Acesso em: 01 ago. 2016.

Relative price variability in Brazil: an analysis of headline and core inflation rates. Nova Economia, v. 35, n. 1, p. 83-100, 2015.

HOLTZ-EAKIN, D.; NEWEY, W.; ROSEN, H. Econometrica, 1988, v. 56, n. 6, p. 1371-1395, 1988.

INSTITUTO BRASILEIRO DE GEOGRAFIA E ESTATÍSTICA. Sistema Nacional de Índices de Preços ao Consumidor. Séries históricas IPCA. Rio de Janeiro, 2016. Disponível em: <ftp:// ftp.ibge.gov.br/Precos_Indices_de_Precos_ao_Consumidor/IPCA/Serie_Historica/ipca_ SerieHist.zip > . Acesso em: 27 jun. 2016.

JARAMILLO, C. F. Inflation and relative price variability: reinstating parks' results. Journal of Money, Credit and Banking, v. 31, n. 3, p. 375-385, 1999.

LANDAU, E.; PEIXOTO, S. S. Pesquisa e planejamento econômico. Pesquisa e Planejamento Econômico, Rio de Janeiro, v. 22, n. 1, p. 125-168, 1992.

LOPES, F. L. Inflação, correção monetária e controles de preços. Revista Brasileira de Economia, Rio de Janeiro, v. 30, n. 4, p. 427-455, 1976.

. Inflação inercial, hiperinflação e desinflação: notas e conjecturas. Revista de Economia Política, São Paulo, v. 5, n. 2, p. 135-151, 1985.

MANKIW, N. G. Small menu costs and large business cycles: a macroeconomic model of monopoly. Quarterly Journal of Economics, Cambridge, MA, US, v. 100, p. 529-37, 1985.

PARKS, R. W. Efficient estimation of a system of regression equations when disturbances are both serially and contemporaneously correlated. Journal of the American Statistical Association, v. 62, n. 308, p. 500-509, June 1967. 95, 1978.

Inflation and relative price variability. Journal of Political Economy, v. 86, n. 1, p. 79-

PARSLEY, D. C. Inflation and relative price variability in the short and long run: new evidence from the United States. Journal of Money, Credit and Banking, v. 28, n. 3, p. 323-341, 1996.

RESENDE, M.; GRANDI, R. Inflação e variabilidade dos preços relativos no Brasil: a questão da causalidade. Revista Brasileira de Economia, Rio de Janeiro, v. 46, n. 4, p. 595-604, 1992.

ROMER, D. The new Keynesian synthesis. The Journal of Economic Perspectives, v. 7, n. 1, p. 5-22, 1993.

SILVA, A. M.; KADOTA, D. K. Inflação e preços relativos: medidas de dispersão. Pesquisa e Planejamento Econômico, Rio de Janeiro, v. 12, n. 1, p. 1-21, 1982.

SIMS, C. Macroeconomics and reality. Econometrica, v. 48, n. 1, p. 1-48, 1980.

VAN HOOMISSEN, T. Price dispersion and inflation: evidence from Israel. Journal of Political Economy, v. 96, n. 6, p. 1303-1314, 1988. 


\section{Apêndice A - Testes econométricos}

Tabela 5 - Seleção de lag do modelo PVAR

\begin{tabular}{c|c|c|c|c|c|c|c}
\hline Período & lag & CD & J & J-valor & MBIC & MAIC & MQIC \\
\hline \multirow{2}{*}{$1994-2016$} & 1 & 0,99 & 131,40 & 0,00 & 36,13 & 107,40 & 81,68 \\
& 2 & 0,99 & 11,34 & 0,18 & $-52,16$ & $-4,65$ & $-21,80$ \\
& 3 & 0,98 & 7,54 & 0,10 & $-24,20$ & $-0,45$ & $-9,02$ \\
\hline \multirow{2}{*}{ 1994m6-1999m7 } & 1 & 0,99 & 55,80 & 0,00 & $-20,38$ & 31,80 & 11,44 \\
& 2 & 0,99 & 17,72 & 0,02 & $-33,06$ & 1,72 & $-11,84$ \\
& 3 & 0,99 & 3,63 & 0,45 & $-21,76$ & $-4,36$ & $-11,15$ \\
\hline \multirow{2}{*}{ 1999m8-2008m12 } & 1 & 0,99 & 117,40 & 0,00 & 32,67 & 93,40 & 70,49 \\
& 2 & 0,99 & 23,83 & 0,00 & $-32,65$ & 7,83 & $-7,43$ \\
& 3 & 0,98 & 4,052 & 0,39 & $-24,19$ & $-3,94$ & $-11,58$ \\
\hline \multirow{2}{*}{ 2009m1-2016m5 } & 1 & 0,98 & 43,71 & 0,00 & $-37,79$ & 19,71 & $-2,26$ \\
& 2 & 0,98 & 10,11 & 0,25 & $-44,22$ & $-5,88$ & $-20,53$ \\
& 3 & 0,96 & 8,02 & 0,09 & $-19,14$ & 0,02 & $-7,29$ \\
\hline
\end{tabular}

Fonte: Elaboração própria a partir de testes de estacionariedade.

Tabela 6 - Testes de estacionariedade para painéis: rpv (1994-2016)

\begin{tabular}{clccccc}
\hline Variável & \multicolumn{1}{c}{ Teste } & Lag & $\mathbf{H}_{\mathbf{0}}$ & $\mathbf{H}_{\mathbf{1}}$ & p-valor & Tendência \\
\hline $\operatorname{rpv}_{1994-2016}$ & Levin-Lin-Chu & 0 & $\begin{array}{c}\text { Raiz } \\
\text { unitária }\end{array}$ & Estacionário & 0,000 & Não \\
$\operatorname{rpv}_{1994-2016}$ & Harris-Tzavalis & 0 & $\begin{array}{c}\text { Raiz } \\
\text { unitária }\end{array}$ & Estacionário & 0,000 & Não \\
$\operatorname{rpv}_{1994-2016}$ & Breitung & 0 & $\begin{array}{c}\text { Raiz } \\
\text { unitária }\end{array}$ & Estacionário & 0,000 & Não \\
$\operatorname{rpv}_{1994-2016}$ & Im-Pesaran-Shin & 0 & $\begin{array}{c}\text { Raiz } \\
\text { unitária }\end{array}$ & Estacionário & 0,000 & Não \\
$\operatorname{rpv}_{1994-2016}$ & Fisher type & 0 & $\begin{array}{c}\text { Raiz } \\
\text { unitária }\end{array}$ & Estacionário & 0,000 & Não \\
$\operatorname{rpv}_{1994 m 7-1999 m 6}$ & Levin-Lin-Chu & 0 & $\begin{array}{c}\text { Raiz } \\
\text { unitária }\end{array}$ & Estacionário & 0,000 & Não \\
$\operatorname{rpv}_{1994 m 7-1999 m 6}$ & Harris-Tzavalis & 0 & $\begin{array}{c}\text { Raiz } \\
\text { unitária }\end{array}$ & Estacionário & 0,000 & Não \\
$\operatorname{rpv}_{1994 m 7-1999 m 6}$ & Breitung & 0 & $\begin{array}{c}\text { Raiz } \\
\text { unitária }\end{array}$ & Estacionário & 0,000 & Não \\
\hline
\end{tabular}


conclusão.

\begin{tabular}{|c|c|c|c|c|c|c|}
\hline Variável & Teste & Lag & $\mathbf{H}_{0}$ & $\mathrm{H}_{1}$ & p-valor & Tendência \\
\hline $\mathrm{rpv}_{1994 \mathrm{~m} 7-1999 \mathrm{~m} 6}$ & Im-Pesaran-Shin & 0 & $\begin{array}{c}\text { Raiz } \\
\text { unitária }\end{array}$ & Estacionário & 0,003 & Não \\
\hline $\mathrm{rpv}_{1994 \mathrm{~m} 7-1999 \mathrm{mb}}$ & Fisher type & 0 & $\begin{array}{c}\text { Raiz } \\
\text { unitária }\end{array}$ & Estacionário & 0,010 & Não \\
\hline $\mathrm{rpv}_{1999 \mathrm{~m} 7-2008 \mathrm{~m} 12}$ & Levin-Lin-Chu & 0 & $\begin{array}{c}\text { Raiz } \\
\text { unitária }\end{array}$ & Estacionário & 0,000 & Não \\
\hline $\mathrm{rpV}_{1999 \mathrm{~m} 7-2008 \mathrm{~m} 12}$ & Harris-Tzavalis & 0 & $\begin{array}{c}\text { Raiz } \\
\text { unitária }\end{array}$ & Estacionário & 0,000 & Não \\
\hline $\mathrm{rpV}_{1999 \mathrm{~m} 7-2008 \mathrm{~m} 12}$ & Breitung & 0 & $\begin{array}{c}\text { Raiz } \\
\text { unitária }\end{array}$ & Estacionário & 0,000 & Não \\
\hline $\mathrm{rpv}_{1999 \mathrm{~m} 7-2008 \mathrm{~m} 12}$ & Im-Pesaran-Shin & 0 & $\begin{array}{c}\text { Raiz } \\
\text { unitária }\end{array}$ & Estacionário & 0,000 & Não \\
\hline $\mathrm{rpv}_{1999 \mathrm{~m} 7-2008 \mathrm{~m} 12}$ & Fisher type & 0 & $\begin{array}{c}\text { Raiz } \\
\text { unitária }\end{array}$ & Estacionário & 0,000 & Não \\
\hline $\mathrm{rpv}_{2009 \mathrm{~m} 1-2016 \mathrm{~m} 5}$ & Levin-Lin-Chu & 0 & $\begin{array}{c}\text { Raiz } \\
\text { unitária }\end{array}$ & Estacionário & 0,000 & Não \\
\hline $\mathrm{rpv}_{2009 \mathrm{ml}-2016 \mathrm{~m} 5}$ & Harris-Tzavalis & 0 & $\begin{array}{c}\text { Raiz } \\
\text { unitária }\end{array}$ & Estacionário & 0,000 & Não \\
\hline $\mathrm{rpv}_{2009 \mathrm{ml}-2016 \mathrm{~m} 5}$ & Breitung & 0 & $\begin{array}{c}\text { Raiz } \\
\text { unitária }\end{array}$ & Estacionário & 0,000 & Não \\
\hline $\mathrm{rpv}_{2009 \mathrm{~m} 1-2016 \mathrm{~m} 5}$ & Im-Pesaran-Shin & 0 & $\begin{array}{c}\text { Raiz } \\
\text { unitária }\end{array}$ & Estacionário & 0,000 & Não \\
\hline $\mathrm{rpv}_{2009 \mathrm{~m} 1-2016 \mathrm{~m} 5}$ & Fisher type & 0 & $\begin{array}{c}\text { Raiz } \\
\text { unitária }\end{array}$ & Estacionário & 0,000 & Não \\
\hline
\end{tabular}

Fonte: Elaboração própria a partir de testes de estacionariedade.

Tabela 7 - Testes de estacionariedade para painéis: IPCA (1994-2016)

\begin{tabular}{|c|c|c|c|c|c|c|}
\hline Variável & Teste & Lag & $\mathbf{H}_{\mathbf{0}}$ & $\mathbf{H}_{1}$ & p-valor & Tendência \\
\hline $\mathrm{IPCA}_{1994-2016}$ & Levin-Lin-Chu & 0 & $\begin{array}{c}\text { Raiz } \\
\text { unitária }\end{array}$ & Estacionário & 0,000 & Não \\
\hline IPCA $_{1994-2016}$ & Harris-Tzavalis & 0 & $\begin{array}{c}\text { Raiz } \\
\text { unitária }\end{array}$ & Estacionário & 0,000 & Não \\
\hline $\mathrm{IPCA}_{1994-2016}$ & Breitung & 0 & $\begin{array}{c}\text { Raiz } \\
\text { unitária }\end{array}$ & Estacionário & 0,000 & Não \\
\hline IPCA $_{1994-2016}$ & Im-Pesaran-Shin & 0 & $\begin{array}{c}\text { Raiz } \\
\text { unitária }\end{array}$ & Estacionário & 0,000 & Não \\
\hline $\mathrm{IPCA}_{1994-2016}$ & Fisher type & 0 & $\begin{array}{c}\text { Raiz } \\
\text { unitária }\end{array}$ & Estacionário & 0,000 & Não \\
\hline $\mathrm{IPCA}_{1994 \mathrm{~m} 7-1999 \mathrm{~m} 6}$ & Levin-Lin-Chu & 0 & $\begin{array}{c}\text { Raiz } \\
\text { unitária }\end{array}$ & Estacionário & 0,000 & Sim \\
\hline
\end{tabular}


conclusão.

\begin{tabular}{|c|c|c|c|c|c|c|}
\hline Variável & Teste & Lag & $\mathbf{H}_{0}$ & $\mathbf{H}_{1}$ & p-valor & Tendência \\
\hline $\mathrm{IPCA}_{1994 \mathrm{~m} 7-1999 \mathrm{~m} 6}$ & Harris-Tzavalis & 0 & $\begin{array}{c}\text { Raiz } \\
\text { unitária }\end{array}$ & Estacionário & 0,000 & Sim \\
\hline $\mathrm{IPCA}_{1994 \mathrm{~m} 7-1999 \mathrm{~m} 6}$ & Breitung & 0 & $\begin{array}{c}\text { Raiz } \\
\text { unitária }\end{array}$ & Estacionário & 0,000 & Sim \\
\hline $\mathrm{IPCA}_{1994 \mathrm{~m} 7-1999 \mathrm{~m} 6}$ & Im-Pesaran-Shin & 0 & $\begin{array}{c}\text { Raiz } \\
\text { unitária }\end{array}$ & Estacionário & 0,000 & Sim \\
\hline IPCA $_{1994 \mathrm{~m} 7-1999 \mathrm{~m} 6}$ & Fisher type & 0 & $\begin{array}{c}\text { Raiz } \\
\text { unitária }\end{array}$ & Estacionário & 0,000 & Sim \\
\hline $\begin{array}{l}\text { IPCA }_{1999 \mathrm{~m} 7}- \\
-2008 \mathrm{~m} 12\end{array}$ & Levin-Lin-Chu & 0 & $\begin{array}{c}\text { Raiz } \\
\text { unitária }\end{array}$ & Estacionário & 0,000 & Não \\
\hline $\begin{array}{l}\text { IPCA }_{1999 \mathrm{~m} 7-} \\
-2008 \mathrm{~m} 12\end{array}$ & Harris-Tzavalis & 0 & $\begin{array}{c}\text { Raiz } \\
\text { unitária }\end{array}$ & Estacionário & 0,000 & Não \\
\hline $\begin{array}{c}\text { IPCA }_{1999 \mathrm{~m} 7-} \\
-2008 \mathrm{~m} 12\end{array}$ & Breitung & 0 & $\begin{array}{c}\text { Raiz } \\
\text { unitária }\end{array}$ & Estacionário & 0,000 & Não \\
\hline $\begin{array}{l}\text { IPCA }_{1999 \mathrm{~m} 7-} \\
-2008 \mathrm{~m} 12\end{array}$ & Im-Pesaran-Shin & 0 & $\begin{array}{c}\text { Raiz } \\
\text { unitária }\end{array}$ & Estacionário & 0,000 & Não \\
\hline $\begin{array}{c}\text { IPCA }_{1999 \mathrm{~m} 7-} \\
-2008 \mathrm{~m} 12\end{array}$ & Fisher type & 0 & $\begin{array}{c}\text { Raiz } \\
\text { unitária }\end{array}$ & Estacionário & 0,000 & Não \\
\hline $\mathrm{IPCA}_{2009 \mathrm{ml}-2016 \mathrm{~m} 5}$ & Levin-Lin-Chu & 0 & $\begin{array}{c}\text { Raiz } \\
\text { unitária }\end{array}$ & Estacionário & 0,000 & Sim \\
\hline IPCA $_{2009 m 1-2016 m 5}$ & Harris-Tzavalis & 0 & $\begin{array}{c}\text { Raiz } \\
\text { unitária }\end{array}$ & Estacionário & 0,000 & Sim \\
\hline $\mathrm{IPCA}_{2009 \mathrm{~m} 1-2016 \mathrm{~m} 5}$ & Breitung & 0 & $\begin{array}{c}\text { Raiz } \\
\text { unitária }\end{array}$ & Estacionário & 0,000 & Sim \\
\hline $\mathrm{IPCA}_{2009 \mathrm{~m} 1-2016 \mathrm{~m} 5}$ & Im-Pesaran-Shin & 0 & $\begin{array}{c}\text { Raiz } \\
\text { unitária }\end{array}$ & Estacionário & 0,000 & Sim \\
\hline $\mathrm{IPCA}_{2009 \mathrm{ml}-2016 \mathrm{~m} 5}$ & Fisher type & 0 & $\begin{array}{c}\text { Raiz } \\
\text { unitária }\end{array}$ & Estacionário & 0,000 & Sim \\
\hline
\end{tabular}

Fonte: Elaboração própria a partir de testes de estacionariedade. 
Tabela 8 - Condição de estabilidade (eigenvalue)

\begin{tabular}{cccccccc}
\hline \multicolumn{2}{c}{$\begin{array}{c}\text { 1994-2016 } \\
\text { Eigenvalue }\end{array}$} & \multicolumn{2}{c}{$\begin{array}{c}\text { 1994m6-1999m7 } \\
\text { Eigenvalue }\end{array}$} & \multicolumn{2}{c}{$\begin{array}{c}\text { 1999m8-2008m12 } \\
\text { Eigenvalue }\end{array}$} & \multicolumn{2}{c}{$\begin{array}{c}\text { 2009m1-2016m5 } \\
\text { Eigenvalue }\end{array}$} \\
Real & Imaginário & Real & Imaginário & Real & Imaginário & Real & Imaginário \\
\hline 0,95 & 0,05 & 0,95 & $-0,06$ & 0,97 & 0 & 0,99 & 0 \\
0,95 & $-0,05$ & 0,95 & 0,06 & 0,85 & 0 & 0,85 & 0 \\
0,48 & 0 & 0,39 & 0 & 0,55 & 0 & 0,34 & 0 \\
, 25 & 0 & 0,30 & 0 & 0,23 & 0 & 0,14 & 0 \\
\hline
\end{tabular}

Fonte: Elaboração própria a partir dos resultados do PVAR.

Recebido em: 19/01/2017.

Aceito em: 27/09/2017. 